\title{
CFD Modelling of Multi-Particulate Flow through Concentric Annulus
}

\author{
Satish Kumar Dewangan \\ Mechanical Engineering Department, \\ National Institute of Technology, Raipur, 492010, Chhatisgarh, India. \\ Vivek Deshmukh \\ Mechanical Engineering Department, \\ National Institute of Technology, Raipur, 492010, Chhatisgarh, India. \\ Corresponding author: vdeshmukh.phd2018.me@nitrr.ac.in
}

(Received December 26, 2018; Accepted August 31, 2019)

\begin{abstract}
In this investigation, flow of multiparticulate lodaded liquid through concentric annulus has been considered with the consideration of rotating inner wall. The present work guides the research studies for petroleum industries in the field of wellbore drilling. The hole-cleaning issue is of utmost importance for the wellbore drilling applications. In oil-well drilling, the horizontal drilling is given more priority. The behaviour of hole cleaning is analyzed through various parameters like axial inlet flow velocity of particulate flow, inner cylinder rotational speed and inlet solid cuttings particle concentration. The effect of these aforementioned parameters on the distribution of solid-phase concentration is studied. Flow is taken as steady, incompressible and multi-particulate slurry flow with primary medium (which carries the solid phase) being water and silica sand with 6 different sizes as the six different phases. The present flow simulation has been done by taking the Eulerian approach. The shape of Silica sand is considered as spherical. ANSYS FLUENT has been used for modelling and solution. Graphs for comparison are obtained using Microsoft Excel.
\end{abstract}

Keywords- Multi-particulate flow, Concentric annulus, Drilling fluids, Slurry flow, Bed formation.

\section{Introduction}

In various industrial processes, fluids are transported through closed conduits. It is prior to design the pipe system for the transportation of a specified quantity of fluid between specified locations with minimum pressure loss considering the initial cost of the piping system. Transportation of particle laden slurries (through the pipeline) is a commonly seen feature for many variety of industrial scenerio such as food processing industries, pharmaceuticals manufacturing industries, chemicals preparation \& process industries and mining industries etc. Globally the scientists and researchers are striving for developing precise models of the velocity profile and solid phase distribution in a slurry pipeline.

Escudier et al. (2002) studied both the concentric annulus and an eccentric annulus (with 80\% eccentricity ratio) with and without center body (inner wall) rotation for the shear thinning fluid flow. Nouri and Whitelaw (1997) had considered axial, radial and tangential velocity components of Newtonian and Non-Newtonian fluid. They concluded that when uniform axial-flow across the annulus occurs the rotation of inner wall had similar behaviour both for Non-Newtonian and Newtonian fluids. Kim and Hwang (2003) have simulated a vortex flow inside the annulus. Cruz and Pinho (2004) researched the concentric annulus with helical flow of fluids considering inner cylinder rotation. Kelessidis and Bandelis (2004) put forward the concept of coiled tube drilling which is efficient in the transportation of drill cuttings however it is still in its early stages. Han et al. $(2008,2009)$ presented the study of a vertical wellbore system in which the slurry is 
constituted of non-Newtonian fluids loaded with solid cutting particles in a tight annulus. The effect of annulus angle, the rate of flow, inner wall rotation was seen on solid distribution and pressure drop. Frigaard and Ngwa (2010) realized that the annular plug fluid was flowing in the influence of buoyant forces in their analysis considering the Hele-Shaw approximation. Gavrilov et al. (2011) worked on annular channels having eccentricity considering the rotation of the inner cylinder. They proposed a numerical algorithm for the simulation of steady, laminar and incompressible fluid.

In all the studies previously mentioned, the approach to reach a solution is different according to the type and nature of the flow. Oil and gas industries generally come up with non-Newtonian flows with turbulent nature. The main role of these fluids is to carry the cuttings generated and when the boring operation is not working then its role is to make sure that solids remain in the suspended state. The nature of the flow of slurry is of utmost importance in hole cleaning. The annular hole is the return passage for slurry and if its cleaning is not done properly then many adversities can occur. The major challenges in oil-well drilling are premature wearing of rotating drill bit, pipe sticking, slow rate of drilling, excessive torque, and drag, etc. Hole cleaning can be made efficient by many parameters like drill string rotation, axial velocity of particulate slurry flow, drilled hole inclination angle, rate of penetration (ROP), drilling fluid physio-chemical property and characteristics of solid cuttings generated \& its morphology. Moreover, the nature of solid particles in the slurry influences the life of the bore parts and its performance as well and because of this many almost all gas and oil-producing houses have to take care of generated cuttings during the process in addition with oil and gas. This causes several problems such as cuttings accumulation in lines or equipment, potential damage to reservoir, sand separation issues, and erosion (Gupta and Pagalthivarthi, 2011).

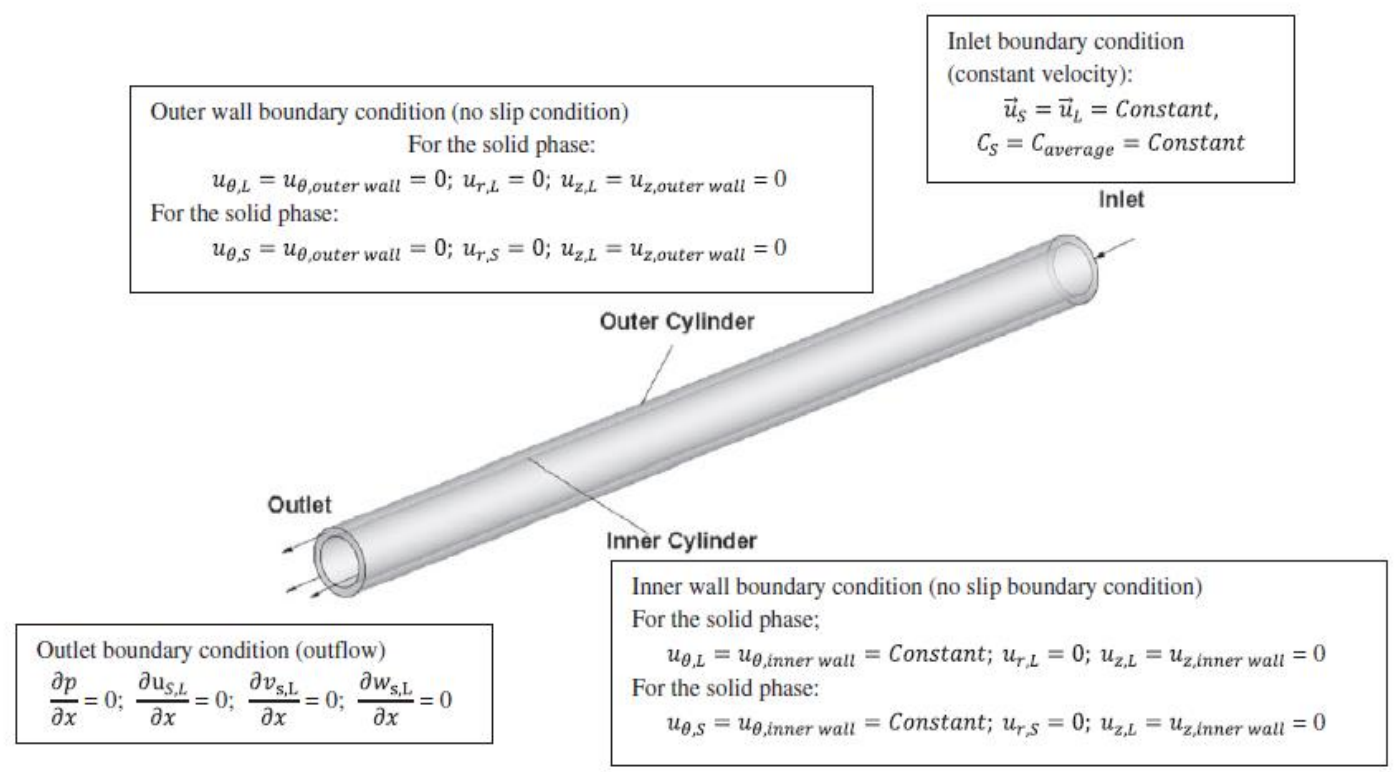

Figure 1. Geometry and boundary conditions 
International Journal of Mathematical, Engineering and Management Sciences

Vol. 5, No. 2, 248-259, 2020

https://doi.org/10.33889/IJMEMS.2020.5.2.020

\section{Problem Definition and Boundary Conditions}

In the present investigation flow features of sand slurry through a concentric wellbore and various parameters like inner wall rotation, linear speed of slurry, the concentration of solid particles, size of solid particles are varied to see the effects on particle size distribution across different planes. Flow is assumed as three-dimensional, incompressible, steady, and turbulent under the considered geometrical and kinematic values taken. Geometry and boundary conditions are shown in Figure 1 for the considered case. For the annulus, the outer diameter $\left(D_{0}\right)$ is $80 \mathrm{~mm}$, inner diameter $\left(D_{i}\right)$ is $60 \mathrm{~mm}$ and length $(\mathrm{L})$ is $1.5 \mathrm{~m}$. Hydraulic mean diameter $\mathrm{D}_{\mathrm{h}}=\left(\mathrm{D}_{\mathrm{o}}-\mathrm{D}_{\mathrm{i}}\right)$ is $20 \mathrm{~mm}$. Centre of the inner cylinder is taken as a reference center for measurement. The meshing of the considered geometry is performed by orthogonal gird for the flow system. A total of 7,14,000 cells has been generated in the computational domain by the distribution of mesh in radial, axial and azimuthal direction. The distribution of finally considered mesh was $50 \times 150 \times 120$ (radial $\times$ azimuthal $\times$ longitudinal, respectively). Simulation is performed in ANSYS-FLUENT using segregated solver. Unlike the coupled solver where the equations are solved in a coupled manner in the segregated solver, equations are solved sequentially.

\section{Mathematical and Numerical Methodology}

In Eulerian model of multiphase flow $\mathrm{n}$ set of equation for momentum and continuity is solved for each phase. Coupling is achieved through the pressure and interphase change coefficient. The coupling depends upon the type of phases involved whether it is granular flow (fluid-solid) or non-granular flow (fluid-fluid). The governing equations for a two-fluid model with two continuous phases are shown below.

$\frac{\partial \alpha_{k} \rho_{k}}{\partial t}+\nabla \cdot\left(\alpha_{k} \rho_{k} u_{k}\right)=0$

$\frac{\partial \alpha_{k} \rho_{k} u_{k}}{\partial t}+\nabla \cdot\left(\alpha_{k} \rho_{k} u_{k} u_{k}\right)=\rho_{k} C_{k} \alpha_{k} \nabla P+\alpha_{k} \nabla \cdot \tau_{k}+\left(\alpha_{k} \rho_{k} g_{k}\right)+S_{k}=0$

$\frac{\partial \alpha_{k}}{\partial t}+\nabla \cdot\left(\alpha_{k} u_{k}\right)=0$

In the above equations, $u$ represents the mean velocity field, $\rho$ represents density, $\alpha$ represents the volume fraction of the phase and $\mathrm{P}$ is the mean pressure shared by the phases. The subscript $k$ refers to the $k^{\text {th }}$ continuous phase. The pipe was first designed in Solid works and then imported to ANSYS workbench. Meshing is done and various zones (inlet, outlet, inner wall, outer wall) were recognized. Present study employs RNG $k$ - $\in$ turbulence model, because it deals very well with the swirling nature of fluid flow. Longtime researches have proved that this is the best model for the study of slurry flow (Pagalthivarthi and Gupta, 2009; Kaushal et al., 2013; Dewangan and Sinha, 2016). For the better study of the regions near thewall, the enhanced wall treatment option was activated. A total of seven phase have been considered which are:

a. Water (Carrier Phase); Density $=998 \mathrm{~kg} / \mathrm{m}^{3}$, Viscosity $=0.001003 \mathrm{~kg} / \mathrm{m}-\mathrm{s}$

b. Silica Sand ( 6 Phases of different sizes); Density $=2650 \mathrm{~kg} / \mathrm{m}^{3}$ (Refer Table 1). 
International Journal of Mathematical, Engineering and Management Sciences

Vol. 5, No. 2, 248-259, 2020

https://doi.org/10.33889/IJMEMS.2020.5.2.020

Table 1. List of cases used for parametric studies of solid concentration

\begin{tabular}{|c|c|c|c|c|c|}
\hline Case & $d_{p}(\mu \mathrm{m})$ & $\% \mathrm{C}_{\mathrm{avg}}$ & $\mathrm{C}_{\mathrm{k}} \%$ age of $\mathrm{C}_{\mathrm{avg}}$ & $R e_{H}$ & $R_{O H}$ \\
\hline $\mathrm{W}_{3}$ & $\begin{array}{c}750,500,250, \\
150,100,50\end{array}$ & $8,12,18$ & $5,10,15,15,25,30$ & $1.75 \mathrm{E} 5$ & $\begin{array}{c}0.02,0.04,0.06,0.08, \\
0.10,0.12\end{array}$ \\
\hline $\mathrm{W}_{4}$ & $\begin{array}{c}750,500, \\
250,150, \\
100,50\end{array}$ & 12 & $\begin{array}{c}20,20,20, \\
15,15,10\end{array}$ & $1.75 \mathrm{E} 5$ & $\begin{array}{l}0.04,0.08 \\
0.12\end{array}$ \\
\hline $\mathrm{W}_{5}$ & $\begin{array}{c}900,700, \\
400,200, \\
125,40\end{array}$ & 12 & $\begin{array}{l}10,15,15, \\
15,20,25\end{array}$ & $1.75 \mathrm{E} 5$ & $0.04,0.08,0.12$ \\
\hline $\mathrm{W}_{6}$ & $\begin{array}{c}900,700, \\
400,200, \\
125,40\end{array}$ & 12 & $\begin{array}{l}16.67,16.67, \\
16,67,16.67, \\
16.67,16.67\end{array}$ & $1.75 \mathrm{E} 5$ & $0.04,0.08,0.12$ \\
\hline $\mathrm{W}_{7}$ & $\begin{array}{c}738,255 \\
180,128, \\
91,38\end{array}$ & 12 & $5,10,20,40,10,5$ & $1.75 \mathrm{E} 5$ & $0.04,0.08,0.12$ \\
\hline $\mathrm{W}_{8}$ & $\begin{array}{c}738,255 \\
180,128, \\
91,38\end{array}$ & 12 & $5,15,30,30,10,10$ & $1.75 \mathrm{E} 5$ & $0.04,0.08,0.12$ \\
\hline $\mathrm{W}_{9}$ & $\begin{array}{c}750,500, \\
250,150, \\
100,50\end{array}$ & 12 & $5,10,15,15,25,30$ & $\begin{array}{c}1.75 \mathrm{E} 5,2.5 \mathrm{E} 5, \\
3.5 \mathrm{E} 5,5 \mathrm{E} 5\end{array}$ & 0.04 \\
\hline
\end{tabular}

In Table $1, d_{p}$ represents the particle size diameter, Re represents the linear Reynolds number and $R o$ represents the ratio of rotational Reynolds number to $R e$

$$
\begin{aligned}
\mathrm{Re}_{\mathrm{H}} & =\frac{\rho v d}{\mu} \\
\mathrm{R}_{\mathrm{OH}} & =\frac{\rho \omega \mathrm{R}^{2}}{\mu * \mathrm{Re}_{\mathrm{H}}}
\end{aligned}
$$

\section{Results and Discussion}

The present analysis has targeted the major problem of the horizontal drilling process, which is the accumulation of cuttings on the lower portion of the hole as this becomes a source of multitudes of drilling defects. Parameters of input and output have been selected as per this consideration only. When the solid particles in the slurry do not get a chance to settle down then it is the only way for thinning of cuttings bed formation. Detailed results considering concentric annulus with inner cylinder rotation for water-sand slurry flow has been presented here. In the present work, the variation of concentration of different solid phases is studied with a change in few crucial parameters such as bulk axial flow velocity (linear velocity) of slurry, rotational speed of inner pipe, and particle size of the solid phases etc. 
International Journal of Mathematical, Engineering and Management Sciences

Vol. 5, No. 2, 248-259, 2020

https://doi.org/10.33889/IJMEMS.2020.5.2.020

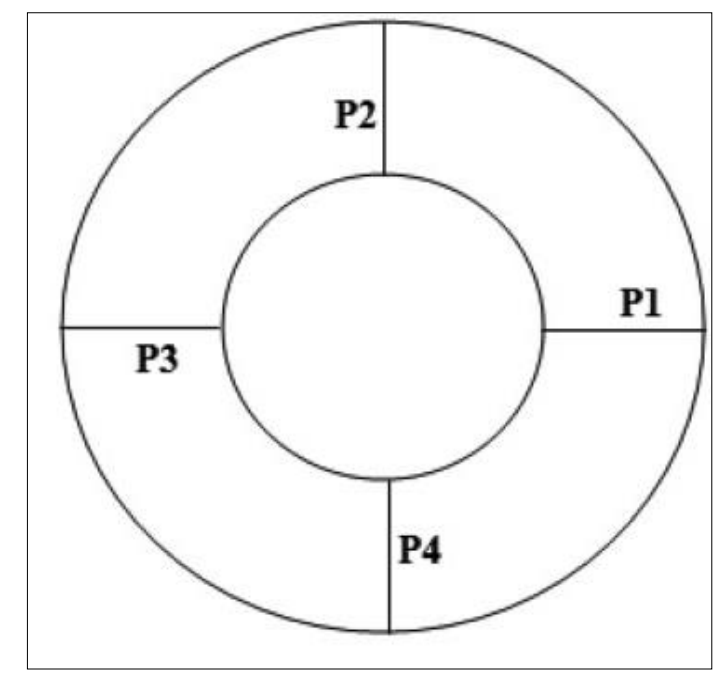

Figure 2. Locations of the radial planes P1, P2, P3 and P4

For insight into simulation within the flow geometry, a cross-section plane at $\mathrm{Z}=1.1 \mathrm{~m}$ is taken and four radial planes are selected along four perpendicular directions as shown in Figure 2. Various cases (Table 1) were run in ANSYS Fluent.

\subsection{Effect of Slurry Flow Velocity on the Volume Concentration}

$\mathrm{W}_{9}$ slurry is simulated with different $\mathrm{Re}$ values that denote variation in axial velocities.From equation number 4 , velocities calculated are : $V_{1}=7.78 \mathrm{~m} / \mathrm{s}$ (corresponding to $R_{1}$ ), $V_{2}=11.58$ $\mathrm{m} / \mathrm{s}$ (corresponding to $R_{2}$ ), $V_{3}=15.55 \mathrm{~m} / \mathrm{s}$ (corresponding to $R_{3}$ ) and $V_{4}=22.25 \mathrm{~m} / \mathrm{s}$ (corresponding to $\mathrm{Re}_{4}$ ).

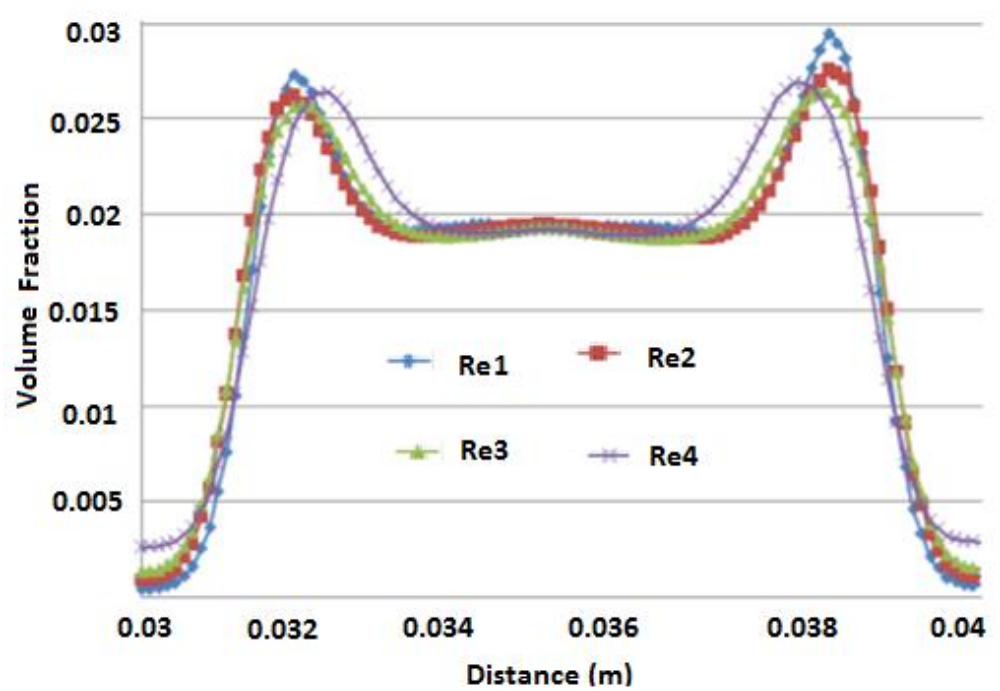

Figure 3. Variation of solid phase volume fraction (for $\mathrm{W}_{9}$ slurry) for different slurry velocities at constant RPM of inner wall along plane 1 
International Journal of Mathematical, Engineering and Management Sciences

Vol. 5, No. 2, 248-259, 2020

https://doi.org/10.33889/IJMEMS.2020.5.2.020

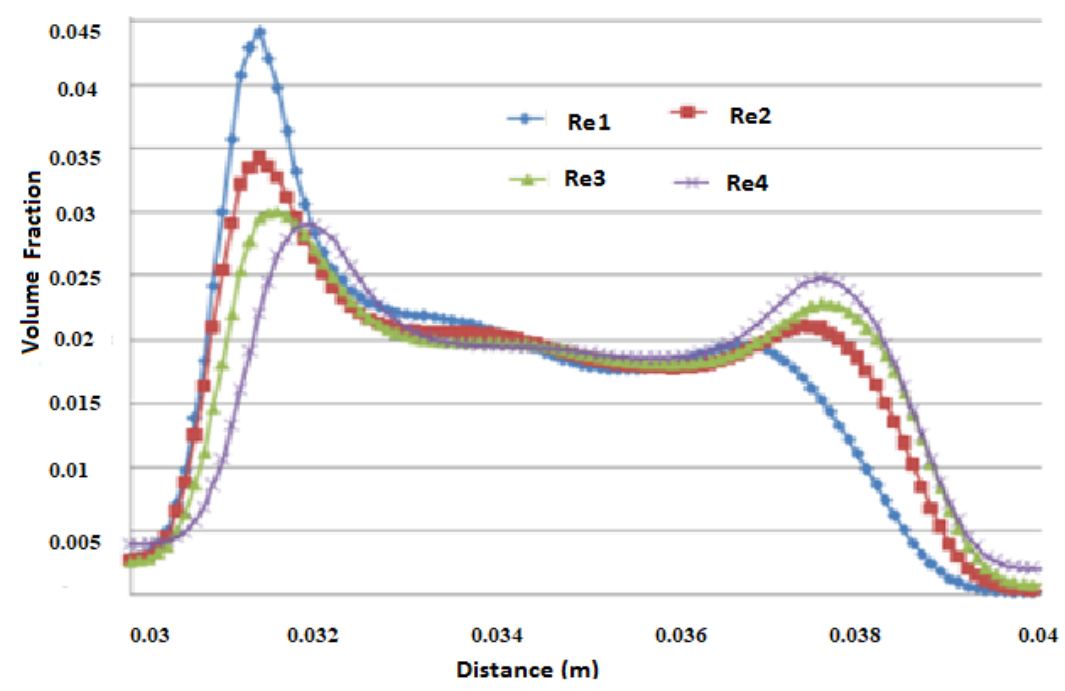

Figure 4. Variation of solid phase volume fraction (for $\mathrm{W}_{9}$ slurry) for different slurry velocities at constant RPM of inner wall along plane 2

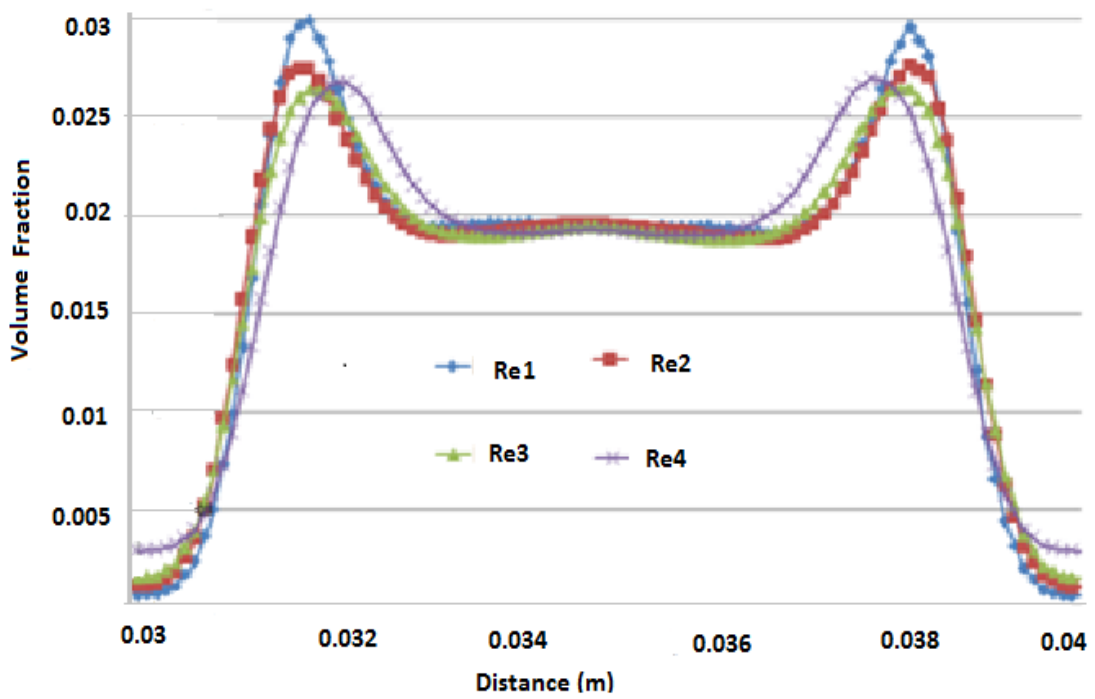

Figure 5. Variation of solid phase volume fraction (for $\mathrm{W}_{9}$ slurry) for different slurry velocities at constant RPM of inner wall along plane 3

From Figures 3-6, it is observed along plane 1 and plane 3, the volume concentration is maximum towards the wall and minimum at the center of the annulus. Along with plane 2 and plane 4, gravity comes into effect and the solid concentration is maximum towards the lower portion of the annulus. As the velocity decreases, the concentration at the bottom of annulus increases. The pattern of solid concentration is similar across plane 1 and 3 and also for plane 2 and 4 hence the results are plotted for plane 1 and 4 in the next investigations. 
International Journal of Mathematical, Engineering and Management Sciences

Vol. 5, No. 2, 248-259, 2020

https://doi.org/10.33889/IJMEMS.2020.5.2.020

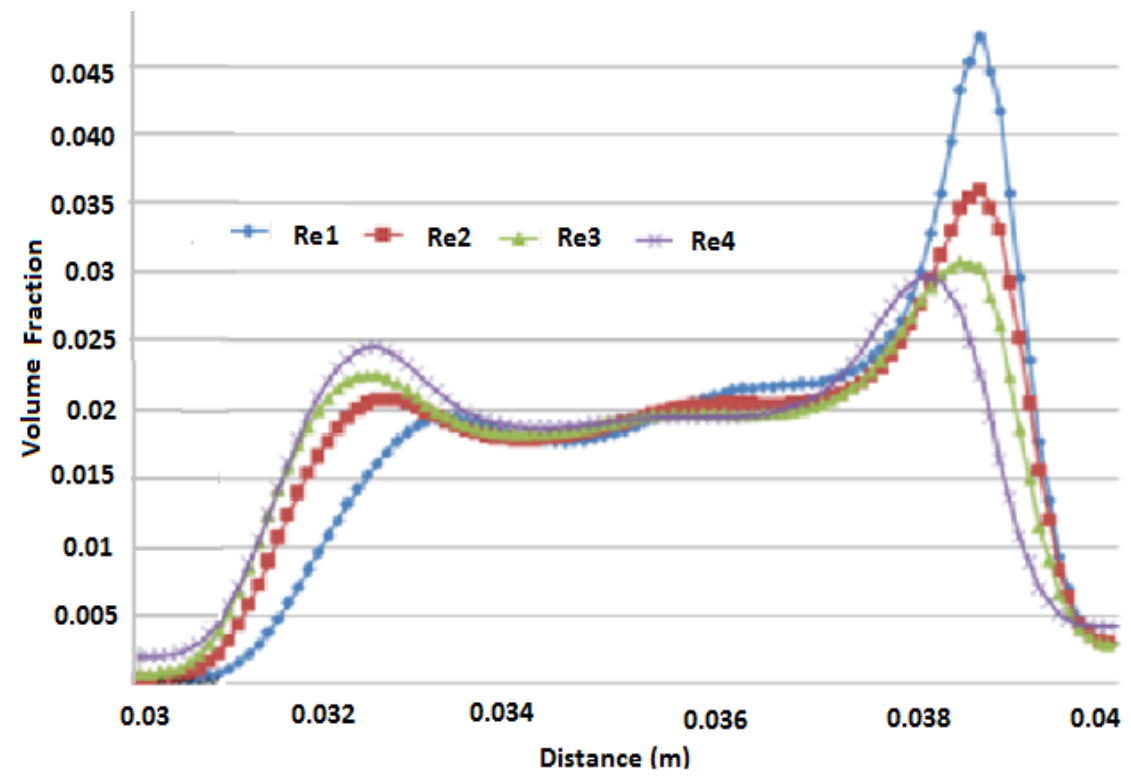

Figure 6. Variation of solid phase volume fraction (for $\mathrm{W}_{9}$ slurry) for different slurry velocities at constant RPM of inner wall along plane 4

\subsection{Effect of Solid Phase Particle Diameter on the Volume Concentration}

The average diameter of solid particles has a great impact on the distribution of particles across the cross-section of the annulus

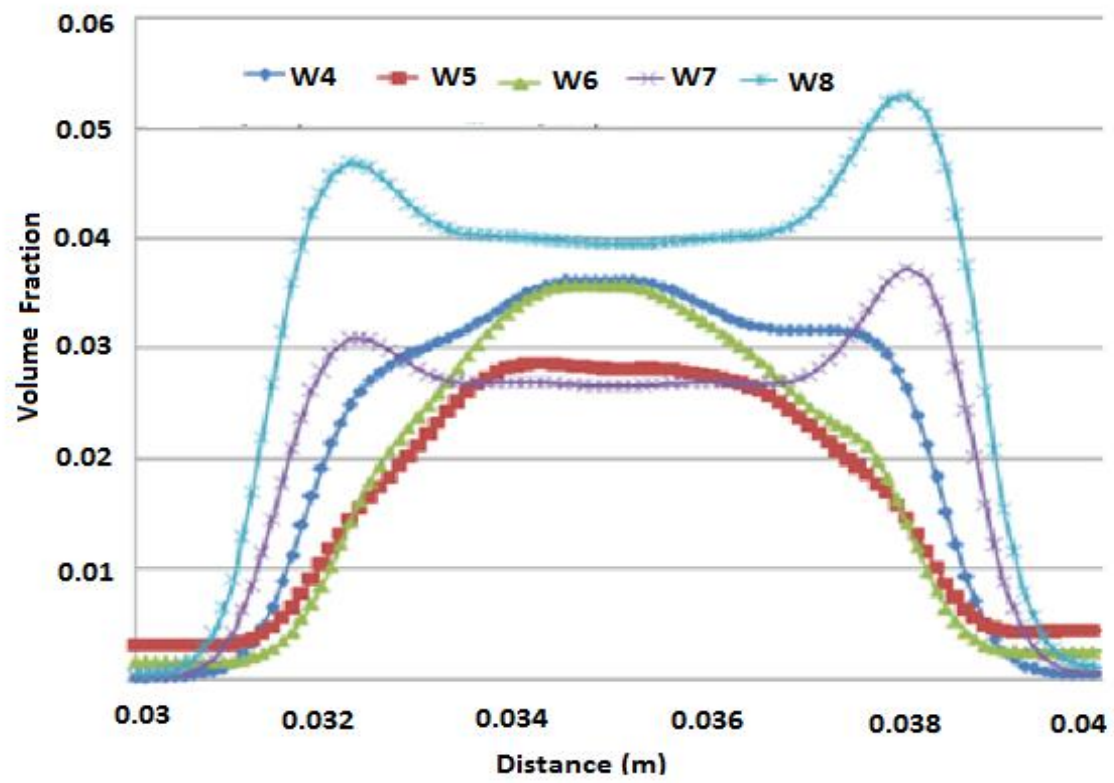

Figure 7. Variation of solid phase volume fraction for particle sizes along plane 1 
International Journal of Mathematical, Engineering and Management Sciences

Vol. 5, No. 2, 248-259, 2020

https://doi.org/10.33889/IJMEMS.2020.5.2.020

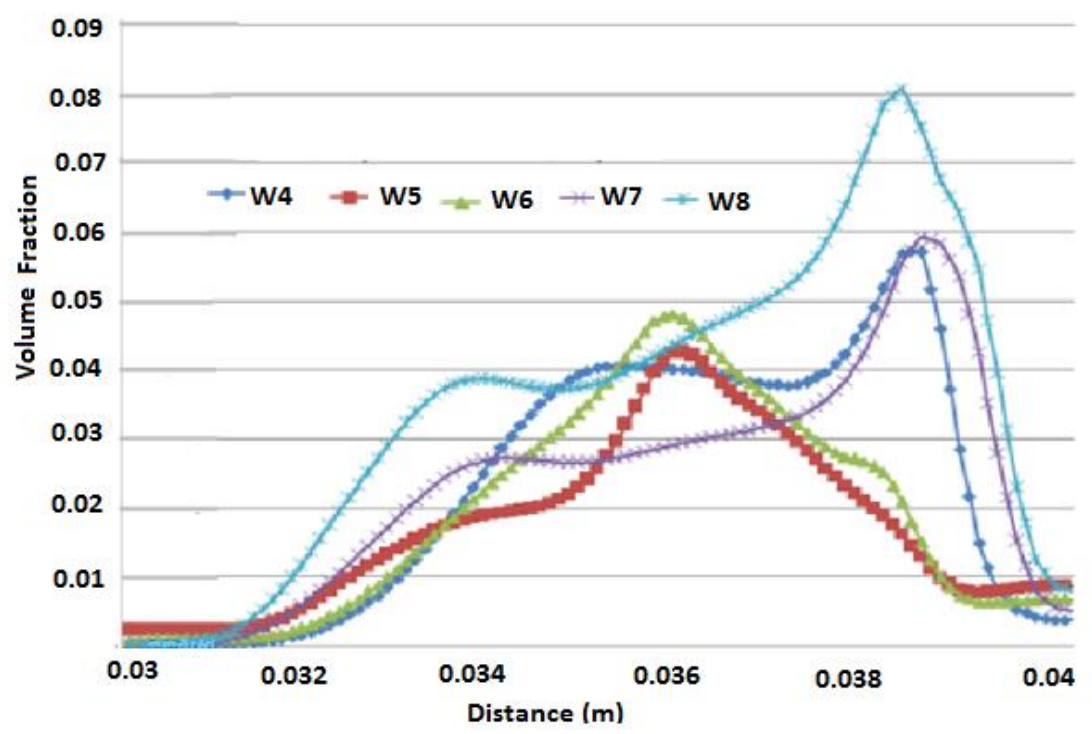

Figure 8. Variation of solid phase volume fraction for particle sizes along plane 4

It is seen in Figures 7-8 that the pattern of volume concentration along the plane is the same for plane 1 and plane 3. The pattern of volume concentration along the is same for plane 2 and plane 4 in reverse direction (because of gravity). Along all the four planes as the average diameter increases, the concentration increases towards the center and for lower diameters volume concentration is high at the walls. The possible reason can be the momentum effect. As the size increases, the mass also increases and due to inner rotation of the wall, solid particles accumulate towards the center which prevents settling at walls.

\subsection{Effect of Rotation of Inner Wall Of Annulus on the Volume Concentration}

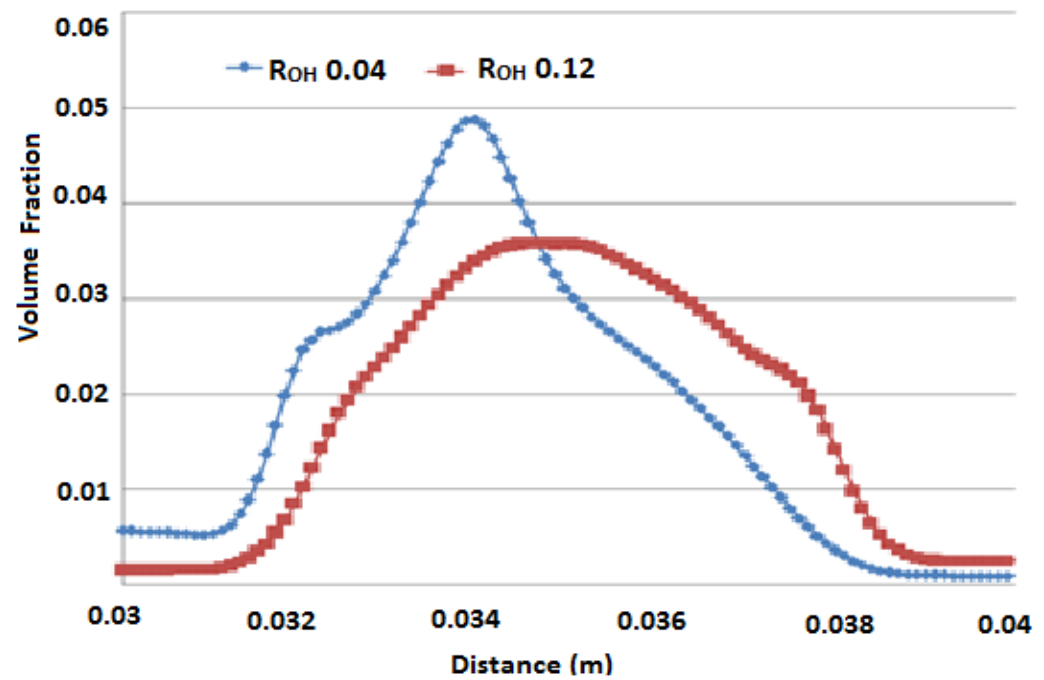

Figure 9. Comparison of solid phase volume fraction for the different rotational speed of inner wall at constant linear velocity $\left[\mathrm{R}_{\mathrm{OH}}=0.04(70 \mathrm{RPM}) ; \mathrm{R}_{\mathrm{OH}}=0.12(200 \mathrm{RPM})\right]$ 
International Journal of Mathematical, Engineering and Management Sciences

Vol. 5, No. 2, 248-259, 2020

https://doi.org/10.33889/IJMEMS.2020.5.2.020

Linear velocity, size of phases being same, volume concentration (fraction) is compared across plane 2 and according to the graph shown in Figure 9, one can conclude that as the rotational speed of inner wall speed increases the phases are more concentrated at the center of the annulus rather than being concentrated at the inner wall due to gravity. Thus higher the rotation speed of the inner wall settling down phenomenon will decrease but there is an upper limit to the RPM which is decided by the system capacity and requirements.

\subsection{Effect of Initial Solid Phase Concentration of a Slurry Sample W3 [I.E. for Constant Particle Diameter $\left.D_{w}\right]$ on the Solid Phase Volume Concentration Distribution}

As the solid phase percentage is increased in the slurry it is predictable that the volume concentration of solid particles will also increase in the proportional amount but the nature of the distribution along the cross-sectional area will be nearly same for all the value of solid phase percentages.Following graphs are plotted for different percentages of solid concentration for $\mathrm{R}_{\mathrm{OH}}$ $=0.02(33 \mathrm{RPM})$. Figures 10-11 show the graphs for $\mathrm{W}_{3}$ slurry with $\mathrm{R}_{\mathrm{OH}}=0.02(33 \mathrm{RPM})$ and linear velocity is also constant i.e. $7.78 \mathrm{~m} / \mathrm{s}$.

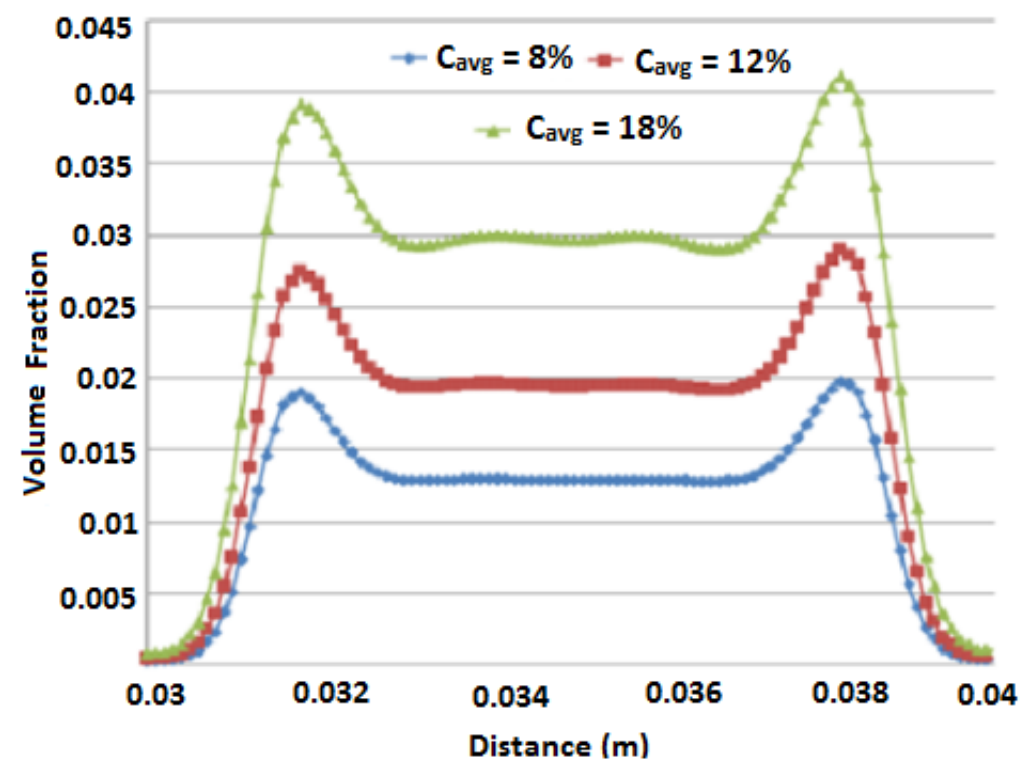

Figure 10. Comparison of solid phase volume fraction for different initial solid phase concentration in slurry sample $\mathrm{W}_{3}$ for $\mathrm{R}_{\mathrm{OH}}=0.02(33 \mathrm{RPM})$ and constant $\mathrm{V}=7.78 \mathrm{~m} / \mathrm{s}$ along Plane 1 
International Journal of Mathematical, Engineering and Management Sciences

Vol. 5, No. 2, 248-259, 2020

https://doi.org/10.33889/IJMEMS.2020.5.2.020

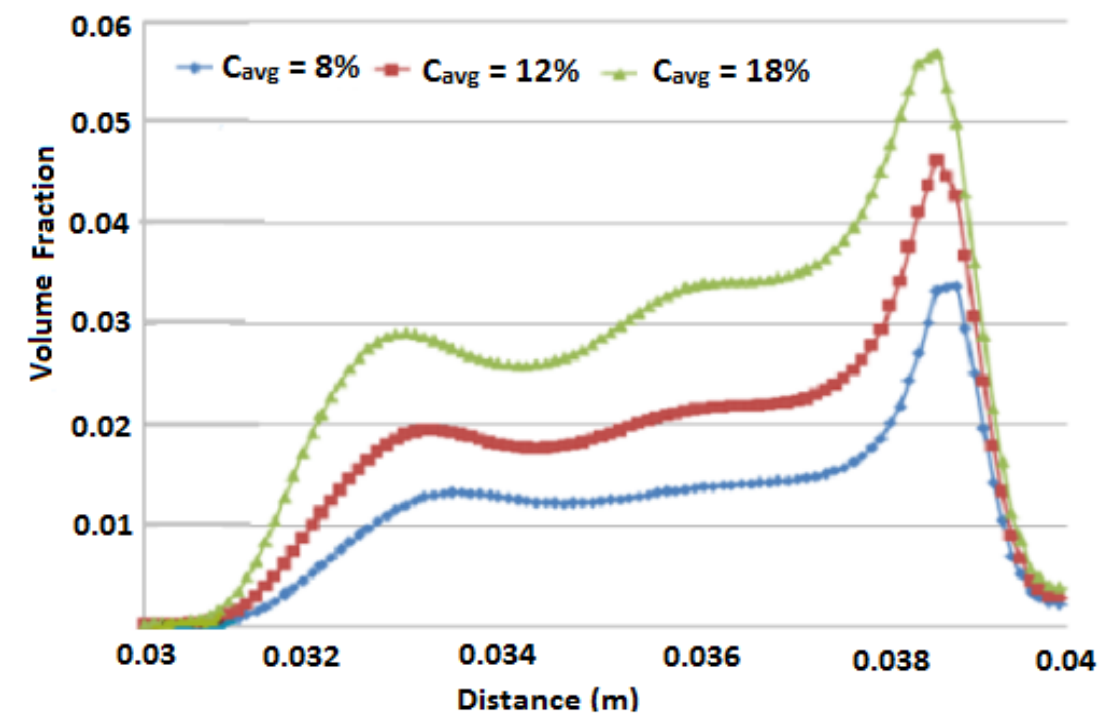

Figure 11. Comparison of solid phase volume fraction for different initial solid phase concentration in slurry sample $\mathrm{W}_{3}$ for $\mathrm{R}_{\mathrm{OH}}=0.02(33 \mathrm{RPM})$ and constant $\mathrm{V}=7.78 \mathrm{~m} / \mathrm{s}$ along Plane 4

The only thing varying is the solid-phase content in the slurry. The nature of the concentration distribution of the solid phase across the cross section is the same for all the three percentages of solid concentration. As the percentage concentration increases in the slurry, the volume fractions of solid particles also increase in the proportional amount.

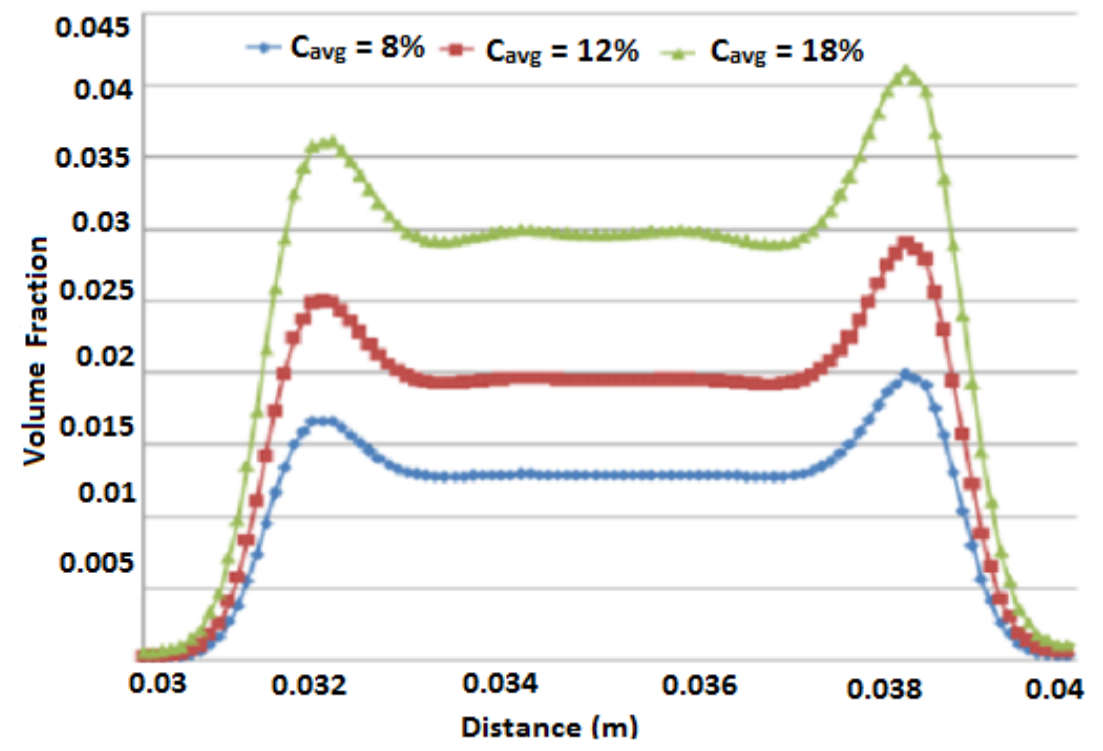

Figure 12. Comparison of solid phase volume fraction for different initial solid phase concentration in slurry sample W3 for $\mathrm{R}_{\mathrm{OH}}=0.08(132 \mathrm{RPM})$ and constant $\mathrm{V}=7.78 \mathrm{~m} / \mathrm{s}$ along Plane 1 
International Journal of Mathematical, Engineering and Management Sciences

Vol. 5, No. 2, 248-259, 2020

https://doi.org/10.33889/IJMEMS.2020.5.2.020

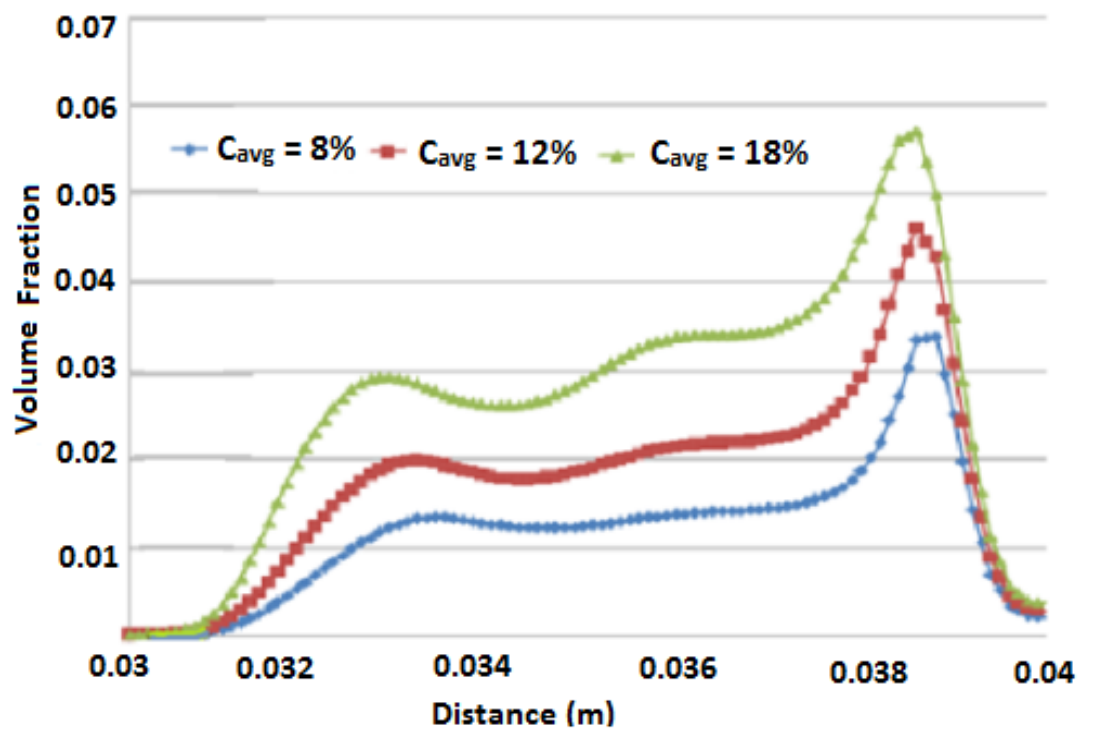

Figure 13. Comparison of solid phase volume fraction for different initial solid phase concentration in slurry sample W3 for $\mathrm{R}_{\mathrm{OH}}=0.08(132 \mathrm{RPM})$ and constant $\mathrm{V}=7.78 \mathrm{~m} / \mathrm{s}$ along Plane 4

The above curves are for $\mathrm{W}_{3}$ slurry with $\mathrm{R}_{\mathrm{OH}}=0.08$ (132 RPM) and linear velocity is also constant i.e. $7.78 \mathrm{~m} / \mathrm{s}$. The only thing varying is the solid-phase content in the slurry. It is clearly seen from Figures 12-13 along plane 1 that with the increases in rotational speed of the inner wall, the volume fraction near the inner wall decreases and happen same for all the percentage concentration of solid phase. Along plane 4, the volume fraction increases towards the outer wall for larger RPM because of the combined effect of gravity and centrifugal force on solid particles.

\section{Conclusions}

The overall conclusion is as follow:

- As the slurry velocity decreases the concentration at the bottom of annulus increases for $\mathrm{W}_{9}$ slurry $(\mathrm{RPM}=200)$

- The concentration increases towards the center and for lower diameter volume concentration is high at the walls ( $\mathrm{V}=7.78 \mathrm{~m} / \mathrm{s}, \mathrm{RPM}=200)$ when the average diameter increases.

- As the rotational speed of inner wall increases the phases are more concentrated at the center of the annulus rather than being concentrated at the inner wall due to gravity. Higher the rotation speed of the inner wall more the settling down phenomenon.

- When the percentage initial solid concentration increases in the slurry at the inlet, the volume fraction of solid particles also increase in the proportional amount.

\section{Conflict of Interest}

The authors confirm that there is no potential conflicts of interest with respect to the research, authorship, and/or publication of this article. 
International Journal of Mathematical, Engineering and Management Sciences

Vol. 5, No. 2, 248-259, 2020

https://doi.org/10.33889/IJMEMS.2020.5.2.020

\section{Acknowledgments}

The authors are grateful to the NIT Raipur (C.G.) India for all letting us to avail the facility of the ANSYS FLUENT software in the computer lab for the simulation and Institute library.

\section{References}

Cruz, D.O.A., \& Pinho, F.T. (2004). Skewed Poiseuille-Couette flows of sPTT fluids in concentric annuli and channels. Journal of Non-Newtonian Fluid Mechanics, 121(1), 1-14.

Dewangan, S.K., \& Sinha, S.L. (2016). Exploring the hole cleaning parameters of horizontal wellbore using two-phase Eulerian CFD approach. The Journal of Computational Multiphase Flows, 8(1), 1539.

Escudier, M. , Oliveira, P.J., Pinho, F., \& Smith, S. (2002). Fully developed laminar flow of nonNewtonian liquids through annuli: comparison of numerical calculations with experiments. Experiments in Fluids, 33(1), 101-111.

Frigaard, I.A., \& Ngwa, G.A. (2010). Slumping flows in narrow eccentric annuli: design of chemical packers and cementing of subsurface gas pipelines. Transport in Porous Media, 83(1), 29-53.

Gavrilov, A.A., Minakov, A.V., \& Dekterev, A.A. (2011). A numerical algorithm for modeling laminar flows in an annular channel with eccentricity. Journal of Applied and Industrial Mathematics, 5(4), 559-568.

Gupta, P.K., \& Pagalthivarthi, K.V. (2011). Comparison of three turbulence models in wear prediction of multi-size particulate flow through rotating channel. International Journal of Mechanical and Mechatronics Engineering, 5(2), 292-299.

Han, S.M., Kim Y.J., Woo, N.S., \& Hwang, Y.K (2008). A study on the solid-liquid two phase helical flow in an inclined annulus. Journal of Mechanical Science and Technology, 22(10), 1914-1920.

Han, S.M., Woo, N.S., \& Hwang, Y.K. (2009). Solid-liquid mixture flow through a slim hole annulus with rotating inner cylinder. Journal of Mechanical Science and Technology, 23(2), 569-577.

Kaushal, D.R., Kumar, A., Tomita, Y., Kuchii, S., \& Tsukamoto, S. (2013). Flow of mono dispersed particles through horizontal bend. International Journal of Multiphase Flow, 52, 71-91.

Kelessidis, V.C. and Bandelis, G.E. (2004). Flow patterns and minimum suspension velocity for efficient cuttings transport in horizontal and deviated wells in coiled-tubing drilling. SPE Drilling \& Completion, 19(4), 213-227, SPE-81746-PA, DOI: 10.2118/81746-PA.

Kim, Y.J. \& Hwang, Y.K . (2003). Experimental study on the vortex flow in a concentric annulus with a rotating inner cylinder. KSME International Journal, 17(4), 562-570.

Nouri, J.M., \& Whitelaw, J.H. (1997). Flow of Newtonian and non-Newtonian fluids in an eccentric annulus with rotation of inner cylinder. International Journal of Heat Fluid Flow, 18(2), 236-246.

Pagalthivarthi, K.V., \& Gupta, P.K. (2009). Prediction of erosion wear in multi-size particulate flow through a rotating channel. Tech Science Press FDMP, 5(1), 93-121. 